\title{
Semiconducting and electrical properties of thin hybrid films from pyrrolyl- and anilynyl-silicon precursors
}

\author{
M. Trueba*, S.P. Trasatti \\ Dipartimento di Chimica, Università degli Studi di Milano, Via Golgi 19, 20133, Milan, Italy
}

\section{A R T ICLE INFO}

\section{Keywords:}

Organic-inorganic hybrid films

Semiconducting properties

Electrical properties

Corrosion protection

\begin{abstract}
A B S T R A C T
The semiconducting and electrical properties of as-deposited and ex-situ irradiated hybrid films on FTO and enriched in Cu 2024-T3 Al alloy substrates, using hydrolyzed solutions of pyrrolyl- (PySi) and anilinyl-silicon (AnSi) compounds, were investigated by means of photocurrent (PCS) and electrochemical impedance (EIS) spectroscopies. AnSi based film is p-type semiconducting while PySi is n-type due to $\mathrm{OH}-\pi$ interactions and charge pinning by silanol $(\mathrm{SiOH})$. The electrical properties depend on the extent and nature of donor-acceptor complexes developed in solution, as well as on the propensity towards $\mathrm{Cu}^{+}(\pi$-ligand) coordination during the surface treatment step. The aniline derivative is more prone to $\mathrm{Cu}-\pi(\mathrm{N})$ complexation, which imparts stability to the buried interface. This, however, turns reactive in the presence of aggressive $\mathrm{Cl}^{-}$due to displacement reactions as the penetration of these species throughout the p-type semiconducting AnSi films is facilitated, contrariwise to the n-type PySi film.
\end{abstract}

\section{Introduction}

Anilynyl- and pyrrolyl-silicon derivatives (Fig. 1) as precursors of hybrid films to protect $\mathrm{Al}$ alloys against corrosion in chloride containing solutions have been widely investigated by our group [1-9]. Films with transparent appearance and thicknesses of $2-5 \mu \mathrm{m}$ are typically obtained by direct-to-metal surface treatment with hydrolyzed methanol-based solutions of PySi and AnSi. The hybrid films behave as "reservoir" (polysiloxane chains) of a "corrosion inhibitor" (aniline or pyrrole moieties), which acts against metal substrate degradation as siloxane linkages fail by back hydrolysis [1-5].

Hydrolyzed structures of PySi are stabilized by $\mathrm{OH}-\pi$ interactions between electron-rich pyrrole ring and electron-deficient silanol group $(\mathrm{SiOH})[1,2,6,9]$. Electropolymerization on inert substrates leads to hybrid films with mixed n-p doping behavior regardless the extent of hydrolysis [7-9], indicating that $\mathrm{OH}-\pi$ donor-acceptor complexes and the charge pinning action on pyrrole (Py) ring by silanol $(\mathrm{SiOH})$ are preserved in the hybrid network. OH- $\pi$ interactions are less effective with the more basic AnSi, which promotes deprotonation and self-condensation of $\mathrm{SiOH}[3-5,8,9]$. The p-type redox behavior of electrogrown films involves anion and proton exchange $[8,9]$, as typically obtained

\footnotetext{
* Corresponding author.

Email address: monica.trueba@unimi.it (M. Trueba)
}

for polyaniline and derivatives [10,11]. Protonation/deprotonation is more likely to involve semiquinoid/benzenoid aniline structures ( $\mathrm{N}-$ $\mathrm{H} \cdots \mathrm{N}$ ) [9]. The electroactivity of the hybrid films supports the shift of oxygen reduction reaction (ORR) to the film/solution interface in aggressive $\mathrm{Cl}$ - environment. The better barrier action of PySi films could be justified by the mixed n-p type redox behavior, limiting the penetration of $\mathrm{Cl}^{-}$through the film thickness towards the metal/film interface [1-5]. Nonetheless, the labile protons of aniline moieties bring about a buffer effect on local alkalization produced by the ORR [4,5]. In addition, the delocalized but not involved in the aromatization lone pair of electrons on the $\mathrm{N}$ atom, and the strong specific orbital $\mathrm{Cu}-\pi(\mathrm{N})$ interactions [12] make the metallo-complexation particularly relevant in the case of Cu-rich Al 2024-T3 [5], leading to a decrease of Al-Cu microgalvanic coupling [4].

Solid state photoactive behavior of the hybrid films has been indicated in Ref. [5]. In particular, AnSi and PySi films on different $\mathrm{Al}$ alloys turned red-brown, and then progressively discolored during exposure to natural light, in correspondence with the increase and the decrease, respectively, of the absorption tail at wavelengths below $450 \mathrm{~nm}$ as monitored by solid UV-vis spectroscopy. These findings point to light-induced photoexcitation of pyrrole and aniline moieties within the hybrid network, promoting redox conversion reactions that alter the doping level. Differently from (electro)chemical doping, 
A<smiles>CO[Si](CCCNc1ccccc1)(OC)OC</smiles>

B<smiles>CO[Si](CCCn1cccc1)(OC)OC</smiles>

Fig. 1. Schematic structures of (a) anilynyl-silicon and (b) pyrrolyl-silicon derivatives.

where permanent electrical conductivity lasts until the charge carriers are purposely removed, photoconductivity lasts until charge carriers are trapped or decay back to the ground state. The generation of free charge carriers by local oxidation and nearby reduction of conducting polymers has been represented by the general equation [10]:

$(\pi \text {-polymer })^{\mathrm{n}}+\mathrm{h} \nu \rightarrow\left[\{\pi \text {-polymer }\}^{+\mathrm{y}}+\{\pi \text {-polymer }\}^{-\mathrm{y}}\right]_{\mathrm{n}}$

where $\mathrm{y}$ is the number of electron-hole pairs. The fact that surface discoloration was less important for the hybrid films deposited on $\mathrm{Al}$ 2024-T3 [5], in particular for the case of PySi films, suggests that copper species act as redox promoters and favor charge trapping.

In this work, photocurrent spectroscopy (PCS) and electrochemical impedance spectroscopy (EIS) were used to investigate the semiconducting and electrical properties of AnSi and PySi hybrid films deposited on FTO and enriched in $\mathrm{Cu} \mathrm{Al}$ 2024-T3 substrates. The effect of controlled white light irradiation was studied in parallel. In addition to methanol-based hydrolyzed solutions of the silicon derivatives (Fig. 1) [1-5,8], treatment solutions containing non-HAP, low-VOC and bio-degradable methylacetate in excess were used for surface modification of Al 2024-T3.

\section{Experimental part}

\subsection{Materials and reagents}

The materials used were glass slides $(50 \mathrm{~mm} \times 50 \mathrm{~mm} \times 2.2 \mathrm{~mm})$ of fluorine doped tin oxide (FTO) $(\approx 7 \Omega /$ sq, Aldrich) and metallic specimens $(20 \times 30 \times 1.5 \mathrm{~mm})$ made from a commercial wrought sheet of 2024-T3 Al alloy (Aviometal Spa) with nominal composition (wt. \%) $4.67 \mathrm{Cu}-1.34 \mathrm{Mg}-0.63 \mathrm{Mn}-0.25 \mathrm{Fe}-0.15 \mathrm{Si}$, bal. Al. Unless otherwise specified, all solutions were prepared with commercially available reagent grade substances and solvents. Aqueous solutions were prepared using water of MilliQ quality.

\subsection{Enrichment in $\mathrm{Cu}$ of $\mathrm{Al} 2024-\mathrm{T3}$}

Before use, Al 2024-T3 surfaces were wet-ground up to 800 grit with abrasive $\mathrm{SiC}$ paper, cleaned in ethanol, and artificially enriched in $\mathrm{Cu}$, according to a reported procedure [13]. Briefly, metallic specimens were immersed in $1.5 \mathrm{~g} / \mathrm{L} \mathrm{NaOH}$ solution for different times ( $\mathrm{t}_{\text {etch }}$ up to $30 \mathrm{~min}$ ), rinsed in large amounts of water and dried with hot air. The enrichment in $\mathrm{Cu}$ was verified by cyclic voltammetry (CV) in $\mathrm{pH} 8.4$ borate buffer solution $\left(8.17 \mathrm{~g} / \mathrm{L} \mathrm{Na}_{2} \mathrm{~B}_{4} \mathrm{O}_{7} 10 \mathrm{H}_{2} \mathrm{O}+7.07 \mathrm{~g} / \mathrm{L} \mathrm{H}_{3} \mathrm{BO}_{3}\right)$, using as-abraded pure $\mathrm{Cu}(99.99 \%)$ as reference material [13]. The corrosion behavior was evaluated in $0.6 \mathrm{M} \mathrm{NaCl}$ by electrochemical impedance spectroscopy. Further experimental details and results are provided as supplementary information (Figs. S1, S2 and Table S1). For the alkaline etching time of $5 \mathrm{~min}$, the enrichment in $\mathrm{Cu}$ of the surface was significant while the consequent increase of surface roughness was negligible in comparison to higher etching times as no capacitive currents at $\mathrm{E}>+0.1 \mathrm{~V}$ (vs $\mathrm{Ag} / \mathrm{AgCl}$ ) were recorded (Fig. S1). In addition, the impedance response differed less from that of the as-abraded substrate (Fig. S2, Table S1), indicating little contribution of flaws on the mixed $\mathrm{Al}-\mathrm{Cu}$ (hydr)oxide layer that are promoted with prolonged alkaline etching [13]. For this condition, enhanced corrosion rather than inhibition and steric hindrance effect slowing down diffusion of corrosion products was indicated [14]. Accordingly, $\mathrm{t}_{\mathrm{etch}}=5 \mathrm{~min}$ was used for the enrichment in $\mathrm{Cu}$ of $\mathrm{Al}$ 2024-T3 surfaces prior to modification with silanes.

\subsection{Hybrid films deposition}

Hydrolyzed solutions of silicon derivatives (Fig. 1), namely $\mathrm{N}$-[3-(trimethoxysilyl) propyl] aniline (AnSi) and N-[3-(trimethoxysilyl) propyl] pyrrole ( $\mathrm{PySi}$ ) were prepared at $4 \mathrm{vol} \%$ in solvent mixtures made of either methanol and water $\left(\mathrm{MeOH} / \mathrm{H}_{2} \mathrm{O}\right.$ 95:5) or of methyl acetate, ethanol and water (MeOAc/EtOH/ $\mathrm{H}_{2} \mathrm{O}$ 50:25:25). The $\mathrm{pH}$ was adjusted to 4 with acetic acid. Solutions were allowed to stand for 3 days for hydrolysis to occur. The typical pink and orange-brown colors of $\mathrm{MeOH}$ based solutions of AnSi and PySi [1-5,8,9] were less intense in the solvent mixture containing polar, aprotic MeOAc in excess, indicating less favored formation of $\mathrm{OH}-\pi$ and $\mathrm{N}-\mathrm{H} \cdots \mathrm{N}$ agglomerates [9]. In the following, treatment solutions are identified by the solvent in excess.

Surface modification of enriched in $\mathrm{Cu} \mathrm{Al} \mathrm{2024-T3} \mathrm{was} \mathrm{carried} \mathrm{out} \mathrm{as}$ in previous works $[1-5,8]$. Metallic specimens were preheated at $120^{\circ} \mathrm{C}$ for $10 \mathrm{~min}$, immersed in a given silane hydrolyzed solution for $3 \mathrm{~min}$, and finally placed in an oven at the temperature indicated above for $1 \mathrm{~h}$. The same procedure, excluding the pre-heating step, was used for the surface modification of FTO substrates. Unless otherwise specified, ex-situ irradiation with white light was carried out under air $\left(\mathrm{O}_{2}\right)$ atmosphere for $2 \mathrm{~h}$, using a $450 \mathrm{~W}$ Xenon lamp (Newport) with maximum excitation range between 400 and $700 \mathrm{~nm}$. Gold-colored surfaces resulted more evident with enriched in $\mathrm{Cu}$ in $\mathrm{Al}$ 2024-T3.

\subsection{Photocurrent spectroscopy (PCS) experiments}

Substrates treated with PySi and AnSi solutions containing $\mathrm{MeOH}$ in excess were used. The modified electrode was positioned vertically in a one-compartment electrochemical cell containing $0.1 \mathrm{M} \mathrm{LiClO}_{4}$ in propylene carbonate (PC), a Pt wire as a counterelectrode, and $\mathrm{Ag} / \mathrm{AgCl}$ as a reference electrode. The monochromatic irradiation of the working surface through the cell quartz window was provided by a $450 \mathrm{~W}$ tungsten lamp (Muller) coupled with a monochromator (Kratos). Photocurrent $\left(\mathrm{I}_{\mathrm{ph}}\right)$ spectra were recorded at constant potential of $-1 \mathrm{~V}(\mathrm{Ue})$ and irradiating wavelengths $\lambda$ from 250 to $450 \mathrm{~nm}$ at intervals of $5 \mathrm{~nm}$, using a PAR 5206 lock-in amplifier interfaced with a computer and locked to a mechanical chopper (frequency of $13 \mathrm{~Hz}$ ) to separate $I_{p h}$ from the total current circulating in the cell. The variation of $\mathrm{I}_{\mathrm{ph}}$ with time during dark/light cycles was recorded for excitation $\lambda$ between 280 and $400 \mathrm{~nm}$ in the presence of $\mathrm{O}_{2} . \mathrm{I}_{\mathrm{ph}}$ data were corrected for the efficiency of the lamp-monochromator system at each wavelength. For selected conditions, cyclic voltammograms between 0.0 and $0.6 \mathrm{~V}$ (vs $\mathrm{Ag} / \mathrm{AgCl}$ ) in $0.25 \mathrm{M} \mathrm{Na}_{2} \mathrm{HPO}_{4}(\mathrm{pH}$ 8.4) were recorded using the electrochemical system indicated above and a computer driven PARSTAT 2263 potentiostat. For some conditions, ex-situ irradiation and photoelectrochemical experiments were carried under inert atmosphere $\left(\mathrm{N}_{2}\right)$. 


\subsection{Electrochemical impedance measurements}

Experiments were carried out with FTO and enriched in $\mathrm{Cu} \mathrm{Al}$ 2024-T3 treated with silane hydrolyzed solutions containing either $\mathrm{MeOH}$ or MeOAc in excess. Ex-situ irradiation of some as-deposited films was performed in air as indicated above. Impedance measurements were performed at open circuit potential $\left(\mathrm{E}_{\mathrm{oc}}\right)$ after $10 \mathrm{~min}$ of conditioning in $0.25 \mathrm{M} \mathrm{Na}_{2} \mathrm{HPO}_{4}$ (pH 8.4), using the electrochemical cell indicated above with electrodes connected to a computer driven PARSTAT 2263 potentiostat/frequency generator. The impedance spectra were recorded from $0.1 \mathrm{~Hz}$ to $65000 \mathrm{~Hz}$ with an AC perturbation amplitude of $\pm 10 \mathrm{mV}$. From preliminary experiments using limits of 0.01 and $0.001 \mathrm{~Hz}$ also, similar spectral features with negligible scatter of low-frequency data and reasonable time of data collection were obtained for $0.1 \mathrm{~Hz}$. EIS experiments in 0.6 and $0.01 \mathrm{M} \mathrm{NaCl}$ solutions were carried out for as-deposited and ex-situ irradiated films on enriched in $\mathrm{Cu} \mathrm{Al}$ 2024-T3. At least two replicated experiments were performed for repeatability check. Fitting of experimental points (goodness $<10^{-3}$ ) was carried out with the help of the ZView ${ }^{\mathrm{TM}}$ software (Scribner Associates Inc.).

\section{Results}

\subsection{Photoactivity and semiconductivity of hybrid films}

Fig. 2a shows the photocurrent spectra of ex-situ irradiated PySi and AnSi films deposited on FTO substrates using $\mathrm{MeOH}$ solutions. A maximum in the photocurrent yield ( $\left.\mathrm{I}_{\mathrm{phmax}}\right)$ at about $320 \mathrm{~nm}$ indicates that the hybrid films are photoactive due to the presence of aniline and pyrrole moieties, supporting previous observations [5]. While the mag-

(a)

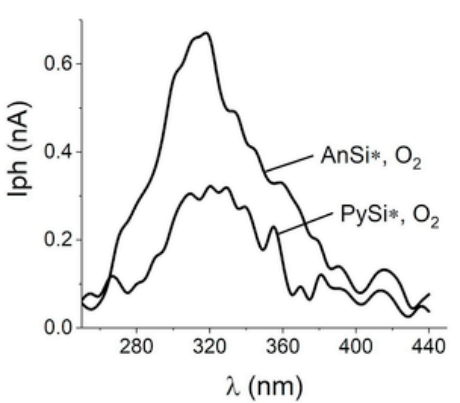

(b)

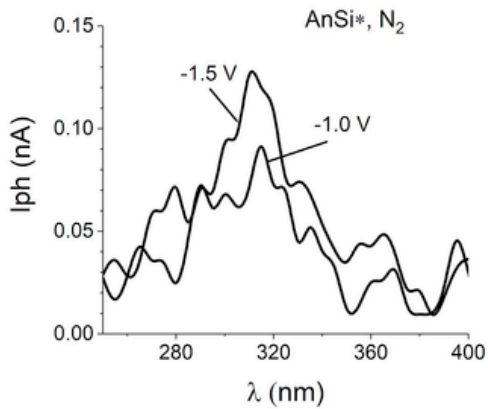

(c)

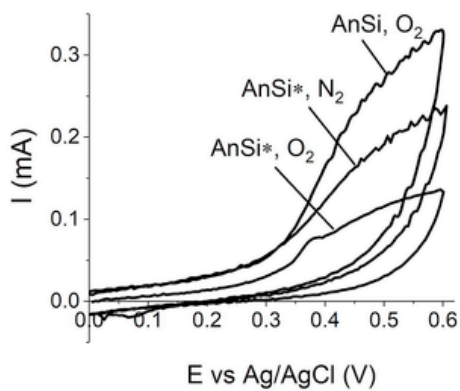

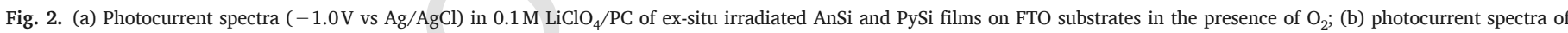

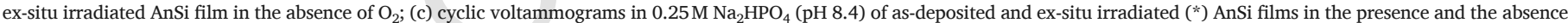
of $\mathrm{O}_{2}$.

(a)

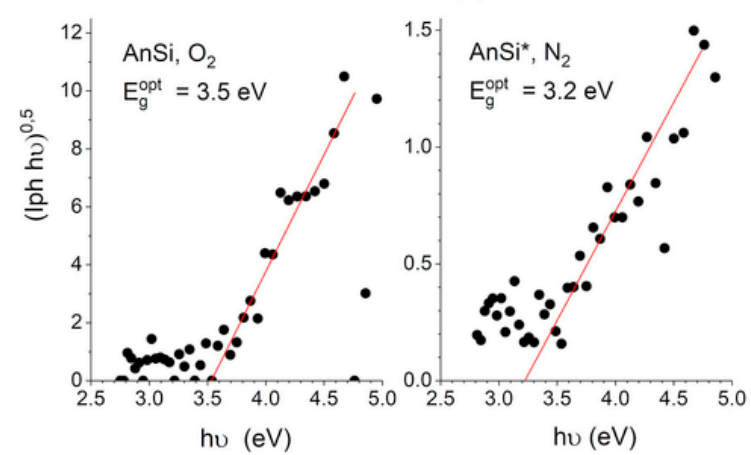

(c)

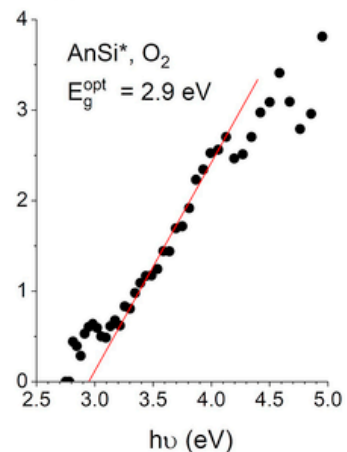

(d)

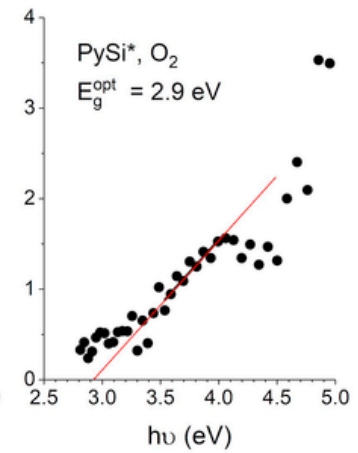

Fig. 3. Plots of $\left(\mathrm{I}_{\mathrm{ph}} \mathrm{h} \nu\right)^{0.5} \mathrm{vs} \mathrm{h} \nu$ derived from the photocurrent spectra ( $-1 \mathrm{~V}$ vs Ag/AgCl, $\left.0.1 \mathrm{M} \mathrm{LiClO}{ }_{4} / \mathrm{PC}\right)$ of as-deposited and ex-situ irradiated (*) hybrid films on FTO. 
be noticed further that $E_{g}{ }^{\text {opt }}$ for ex-situ irradiated films of AnSi and PySi is almost the same (Fig. 3c and d). The smaller $\mathrm{I}_{\text {phmax }}$ for PySi films (Fig. 2a) could be attributed to a less defective hybrid film as a result of long-range $\mathrm{OH}-\pi$ interactions and charge pinning by $\mathrm{SiOH}$.

$E_{g}{ }^{\text {opt }}$ was estimated also for the films deposited on pure $\mathrm{Al}(99.9 \%)$, pure $\mathrm{Cu}(99.9 \%)$ and $\mathrm{Al}$ 2024-T3 (as-abraded and 5-min etched) substrates. Ex-situ irradiation and photoelectrochemical experiments $(-1 \mathrm{~V}$ in $0.1 \mathrm{M} \mathrm{LiClO}_{4} / \mathrm{PC}$ ) were carried out in the presence of $\mathrm{O}_{2}$. The characteristic Fowler emission threshold of aluminum $\left(\mathrm{E}_{\text {th }}=2.2 \mathrm{eV}\right)[17,18]$ was obtained for pure $\mathrm{Al}$ and $\mathrm{Al} 2024-\mathrm{T} 3$ substrates, pointing to internal photoemission processes at the buried metal/silane interface. $E_{g}{ }^{o p t}$ values for as-deposited and ex-situ irradiated films on pure $\mathrm{Cu}$ were about $3.6 \mathrm{eV}$ and $2.9 \mathrm{eV}$, respectively, as shown for AnSi films in Fig. 4. The similarity of $E_{g}{ }^{\text {opt }}$ values with those obtained for the case of FTO substrates (Fig. 3) suggests that $\mathrm{Cu}-\pi(\mathrm{N})$ interactions play a minor role on photo-doping processes. Considering that silanol adsorption and heteronuclear oxane bonding are much less favored on FTO and $\mathrm{Cu}$ substrates, the internal photoemission for the case of $\mathrm{Al}$ substrates might result from traps generated at the Al-O-Si interface [19].

The time dependence of $\mathrm{I}_{\mathrm{ph}}$ during dark/light cycles at different excitation wavelengths ( $\lambda$ between 280 and $400 \mathrm{~nm}$ ) [17,18] was determined for the ex-situ irradiated films on FTO substrates in the presence of $\mathrm{O}_{2}$. The shape of $\mathrm{I}_{\mathrm{ph}}-\mathrm{t}$ plots (Fig. 5) indicates that the photocurrent generation process is quite instantaneous and relatively stable for a given $\lambda$. However, $\mathrm{I}_{\mathrm{ph}}$ decreases with light and increases with dark for

(a)

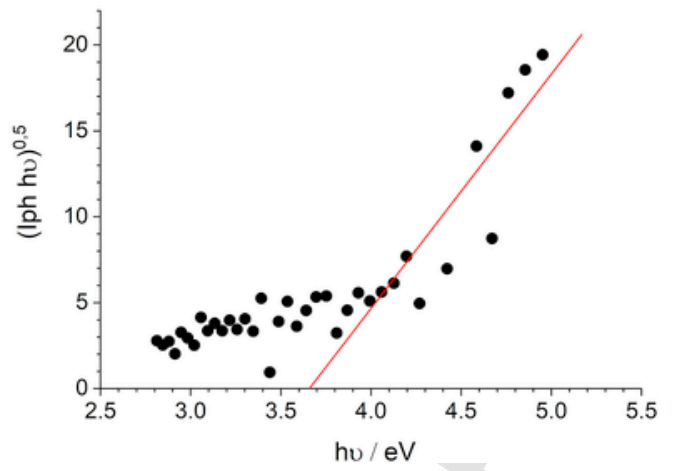

the case of AnSi film (Fig. 5a, inset). The cathodic $\mathrm{I}_{\mathrm{ph}}$ generated with light on is indicative of $\mathrm{p}$-type semiconductivity, i.e., large $\mathrm{h}^{+}$concentration. Conversely, $\mathrm{I}_{\mathrm{ph}}$ increases as light is turned on (anodic $\mathrm{I}_{\mathrm{ph}}$ ) in the case of PySi film (Fig. 5b, inset), corresponding to n-type semiconducting behavior (large $\mathrm{e}^{-}$concentration), i.e., the charge is accumulated (or trapped) rather than depleted with photo-oxidation. The dynamics of the charging/discharging process is likely to be also different. $\mathrm{I}_{\mathrm{ph}}$ decreases less steeply as the light is turned on for the p-type AnSi film, suggesting slow depletion of charge. Fast accumulation of charge is indicated for the n-type PySi film by the sudden, rather than gradual, increase of $\mathrm{I}_{\mathrm{ph}}$ towards the steady state in a given light on/off cycle. These results are consistent with the different chemical behavior of hybrid silanes in solution, the structural properties of as-deposited films, and the solid state processes of electrodeposited films $[1-5,8,9]$. As mentioned before, the more basic anilynyl silicon derivative promotes deprotonation and condensation of $\mathrm{SiOH}$. Thus, homo-functional aggregation via propyl-tethered Si-O-Si chains and semiquinoid/benzenoid aniline hybrid structures rather than hydrogen bonded $\mathrm{O} \cdots \mathrm{H}-$ $\mathrm{N}$ complexes (i.e. nitrenium radical cations $\mathrm{NH}^{+}$stabilized as zwitterions $\left.\left[\mathrm{C}_{6} \mathrm{H}_{5} \mathrm{NH}^{\bullet+}\left(\mathrm{CH}_{2}\right)_{3} \mathrm{Si}\left(\mathrm{O}^{-}\right)(\mathrm{OH})_{2}\right]\right)$, prevails in solution and in the condensed phases $[2-5,9]$. Conversely, non-covalent $\mathrm{OH}-\pi$ interactions between electron-deficient $\mathrm{SiOH}$ and electron-rich pyrrole ring limit the self-condensation of $\mathrm{SiOH}[1,2,6,9]$. The $\mathrm{n}$-type semiconducting behavior of the chemically deposited films corroborates the predilection for cooperative long-range $\mathrm{OH}-\pi$ interactions and charge trapping.

(b)

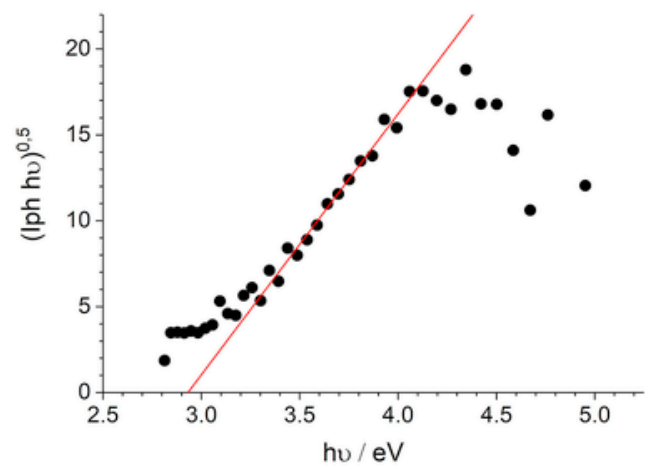

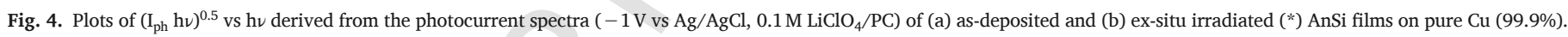

(a)

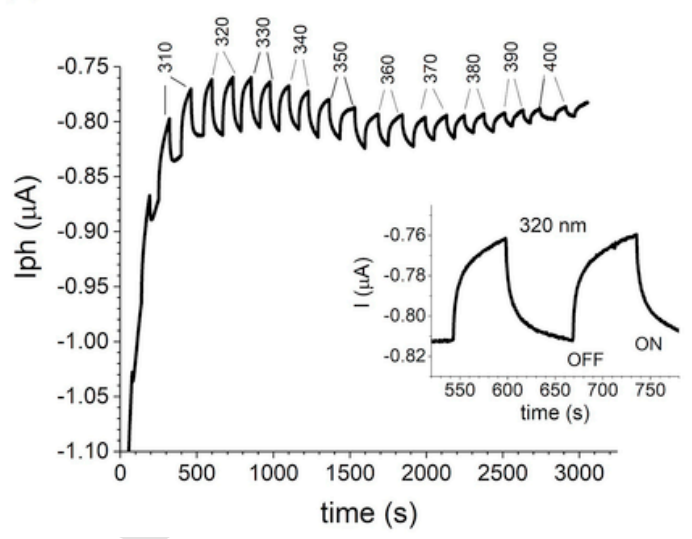

(b)

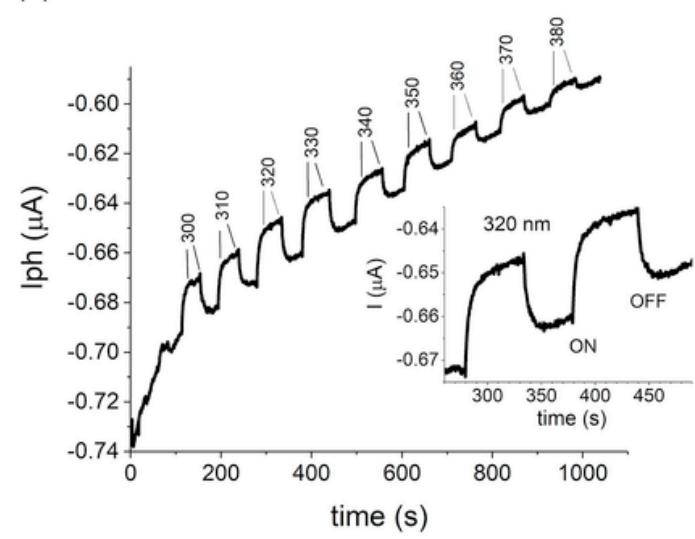

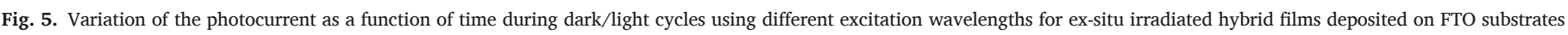
and polarized at $-1.0 \mathrm{~V}$ (vs Ag/AgCl) in $0.1 \mathrm{M} \mathrm{LiClO}_{4} / \mathrm{PC}$ : (a) $\mathrm{AnSi}$; (b) PySi. 


\subsection{Impedance behavior of the hybrid films in $\mathrm{Na}_{2} \mathrm{HPO}_{4}$}

The Nyquist diagrams in $\mathrm{Na}_{2} \mathrm{HPO}_{4}$ (pH 8.4) for untreated and modified with hybrid silanes FTO substrates were collected at the open circuit potential, which was closely equal for the different investigated systems $\left(\mathrm{E}_{\mathrm{oc}}=-0.050 \pm 0.003 \mathrm{~V}\right.$ vs $\left.\mathrm{Ag} / \mathrm{AgCl}\right)$. One time dependent process was indicated by the depressed capacitive semicircle dominating the whole frequency domain, being related to double layer charg-

(a)

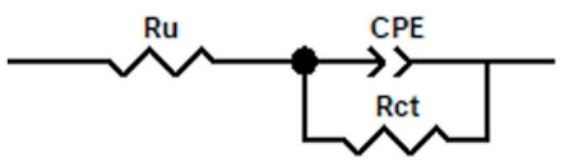

(b)

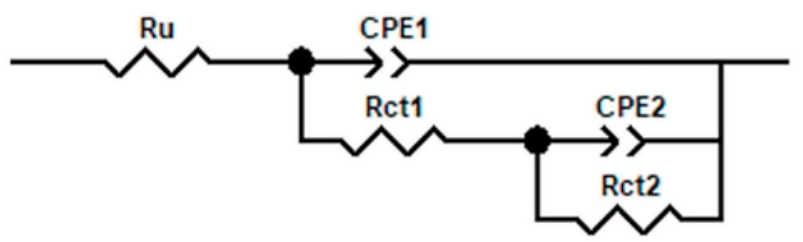

(c)

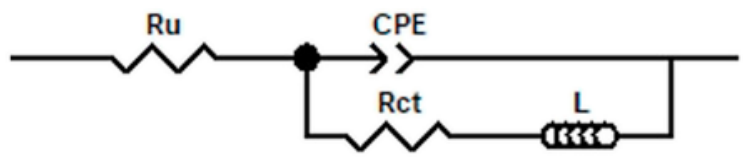

Fig. 6. Equivalent circuits used for fitting EIS spectra. Circuit elements: $\mathrm{Ru}$ - uncompensated resistance, $\mathrm{R}_{\mathrm{ct}}$ - charge transfer resistance, CPE - constant phase element, $\mathrm{L}$ - inductance. See the text for clarity.

(a)
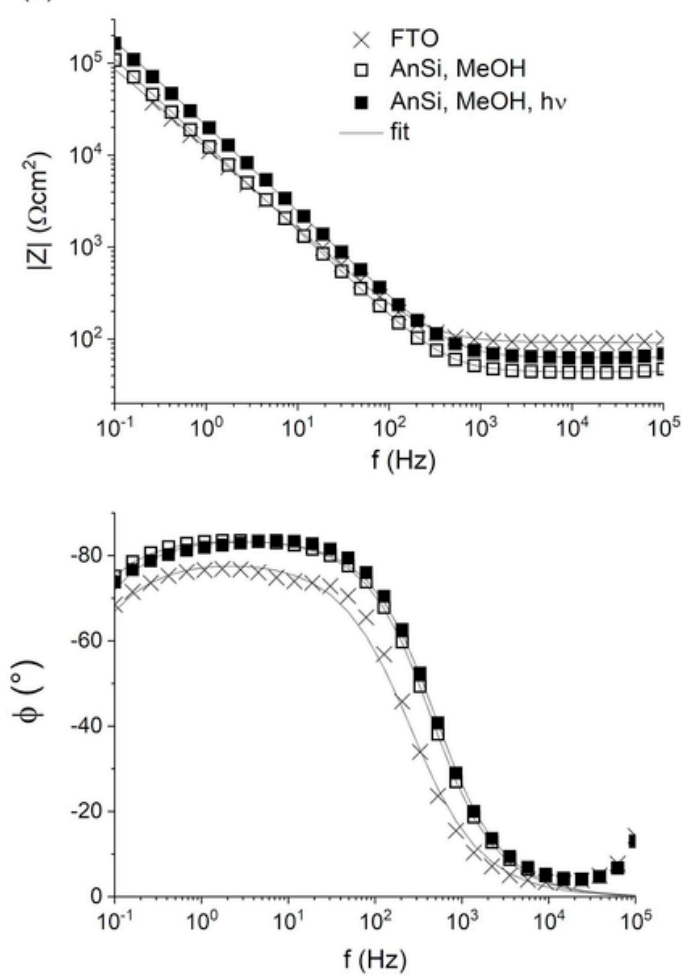

ing of bare and filmed surfaces. The equivalent circuit depicted in Fig. $6 a$ fitted best the experimental points, where $R_{u}$ estimates the uncompensated resistance of the electrolyte, $\mathrm{R}_{\mathrm{ct}}$ represents the charge transfer resistance of bare or filmed FTO, and the constant phase element (CPE) stands for the non-ideal capacitive behavior of the corresponding interface as a result of the distribution of reactivity due to surface heterogeneity [20]. Fitting results are provided as supplementary data (Table S2) while some representative spectra (Bode representation) are reported in Fig. 7.

The fitting results are graphically compared in Fig. 8, where the values of $\mathrm{R}_{\mathrm{ct}}$ and of CPE paramters $\mathrm{Q}$ and $\alpha$ of the uncoated substrate are indicated by arrows near the $\mathrm{y}$ axes in $(\mathrm{a}, \mathrm{b})$ and by a dotted line in (c). Surface modification with PySi gives a more resistive barrier system, as indicated by the increase of $R_{c t}$ and the decrease of $Q$ (Fig. 8a). Charge transfer properties tend to be restored with ex-situ photo-oxidation, in particular for PySi(MeOH)* with similar $\mathrm{R}_{\mathrm{ct}}$ and $\mathrm{Q}$ values to those of uncoated FTO (Fig. 8a). This is justified by the smaller band-gap of $\mathrm{OH}-\pi$ domor-acceptor complexes that are promoted with hydrolysis [6-9], leading to an interpenetrated $\sigma-\pi$ conjugated hybrid network [6-9]. Less facilitated is the photo-oxidation of the films deposited using MeOAc solutions (Fig. 8a) containing higher amount of non-hydrolyzed moities, unless electrochemically oxidized albeit the electrodeposited films present p-type rather than mixed n-p redox behavior [7-9]. The differences above are supported by the smaller contribution of the distribution of reactivity of $\mathrm{PySi}(\mathrm{MeOH})(\alpha>0.85)$ in comparison to PySi(MeOAc) $(\alpha<0.85)$ (Fig. 8c).

The species developed with hydrolysis determine the charge transfer behavior of the chemically deposited films of AnSi as well (Fig. 8b and $c$ ). The variation of $\mathrm{R}_{\mathrm{ct}}, \mathrm{Q}$ and $\alpha$ for the of $\mathrm{AnSi}(\mathrm{MeOAc})$ treatment reproduces rather well that obtained for PySi(MeOAc) (Fig. 8a). Conversely, for $\mathrm{AnSi}(\mathrm{MeOH}), \mathrm{R}_{\mathrm{ct}}$ and $\mathrm{Q}$ values differ less from those of uncoated FTO and change little with ex-situ photo-oxidation while the distribution of surface reactivity is negligible $(\alpha>0.9)$ (Fig. 8c). This

(b)
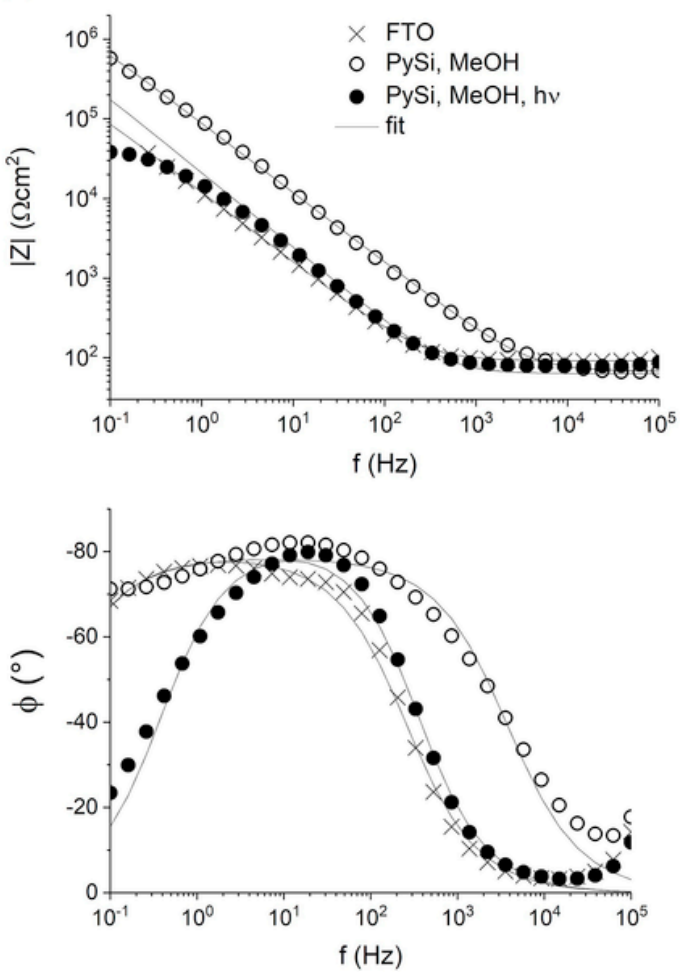

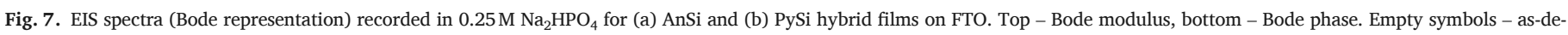
posited films; filled symbols - ex-situ irradiated films (2h); cross symbols - uncoated FTO. 
(a)

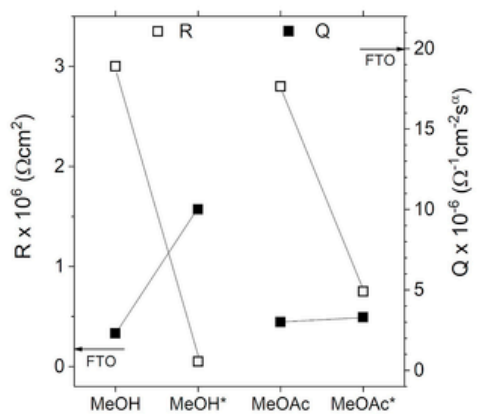

(b)

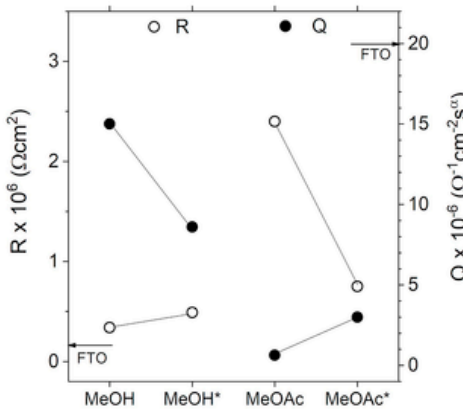

(c)

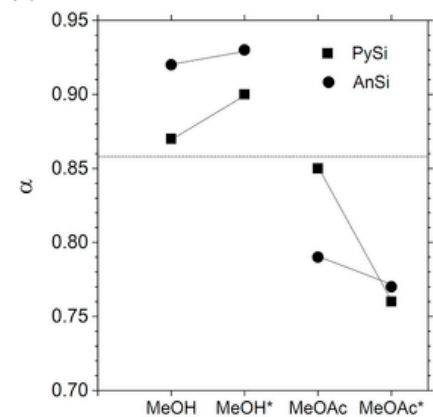

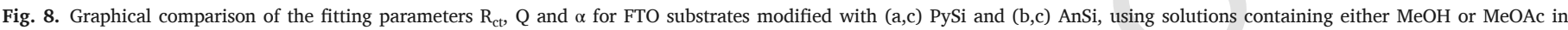
excess. The symbol (*) indicates ex-situ irradiation with white light. Arrows near the y axes in (a,b) and the dotted line in (c) indicate the values of $\mathrm{R}_{\mathrm{c}}$, $\mathrm{Q}$ and $\alpha$ for uncoated FTO.

points to smaller energetic barriers for charge transfer due to the presence of redox active semiquinoid/benzenoid aniline structures [3-5,9].

The origin of the CPE behavior, which may arise from the distribution along or normal to the electrode surface of time-constants for charge-transfer reactions, being associated to a distributions of physical properties (structure, reactivity, dielectric constants, and resistivity), was further studied by considering the effective capacitance $\mathrm{C}_{\text {eff }}$ related to surface and normal distributions of properties, according to the Eqs. (3) and (4), respectively [20]:

$$
\begin{aligned}
& C_{\text {eff }}=Q^{1 / \alpha} \times R_{u}{ }^{(1-\alpha) / \alpha} \\
& C_{\text {eff }}=Q^{1 / \alpha} \times R_{c t}{ }^{(1-\alpha) / \alpha}\left(R_{u}<<R_{c t}\right)
\end{aligned}
$$

The trend of $\mathrm{C}_{\text {eff }}$ with ex-situ irradiation for a given treatment condition reproduces rather well those of Q (Fig. 8a,b and 9), but the differences between $\mathrm{Q}$ and $\mathrm{C}_{\text {eff }}$ calculated with Eq. (4) are smaller. Thus, the CPE behavior arises principally from the distribution of reactivity throughout the hybrid film. The higher charge exchange capability is confirmed for the case of $\mathrm{MeOH}$ treatments, being in accordance with the incorporation of donor-acceptor charge transfer complexes, namely $\mathrm{OH}-\pi$ and $\mathrm{N}-\mathrm{H} \cdots \mathrm{N}$ aggregates for PySi and AnSi, respectively within the hybrid network.

Nyquist diagrams collected for modified Al 2024-T3 ( $\left.\mathrm{t}_{\text {etch }}=5 \mathrm{~min}\right)$ at $\mathrm{E}_{\mathrm{oc}}(-0.25 \pm 0.05 \mathrm{~V}$ vs $\mathrm{Ag} / \mathrm{AgCl})$ showed two closely overlapped capacitive semicircles for all the treatment conditions except AnSi(MeOAc). In this case, as for the uncoated substrate, a single capacitive loop was obtained. The experimental data fitted best circuit models with two R |CPE elements in series (Fig. 6b) and one R\|CPE (Fig. 6a), respectively. The Bode plots (Fig. 10) show an increase of the global impedance with surface modification and closely overlapped $\phi$ peaks, suggesting charge storage and internal charge transfer for equilibration. The $\phi$ peaks detected at higher frequencies

(a)

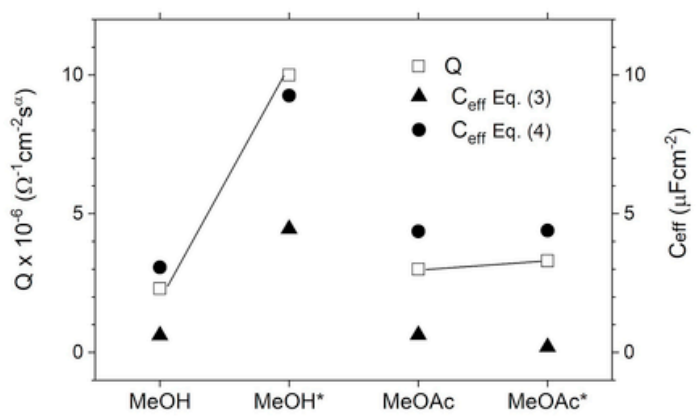

for $\mathrm{AnSi}(\mathrm{MeOH})$ (Fig. 10a) point to faster charge transfer kinetics (smaller relaxation time constants) for the resulting hybrid film. In addition, the breakpoint frequency $\left(\phi \approx 45^{\circ}\right)$ at about $10^{4} \mathrm{~Hz}$ manifests participation of ionic species in charge transfer processes. The kinetics of charge transfer is enhanced with ex-situ irradiation for PySi films (Fig. $10 \mathrm{c}$ and $\mathrm{d}$ ).

Based on the fact that local alkalization by ORR does not drive corrosion of Al 2024-T3 at open circuit in phosphate buffer solution [13], the two time constants in the EIS spectra of the hybrid films indicate the formation of a two-layer hybrid film upon modification of enriched in $\mathrm{Cu}$ surfaces. The analysis of fitting results (Table S3) indicated that the inner layer is more resistive than the outer layer $\left(R_{2}>R_{1}\right.$ ) (Fig. 6b), whereas the resistance of the latter layer differed little from that of the unocated substrate $\left(\mathrm{R}_{1} \approx \mathrm{R}\right)$ for most conditions. In addition, $\alpha_{1}>0.80>\alpha_{2}$ (Table S3) which points to a less inhomogeneous distribution of active sites in the inner layer. For the case of $\mathrm{AnSi}(\mathrm{MeOAc})$ treatment leading to hybrid films with one time dependent process (Fig. 6a, Fig. 10b), the corresponding $\mathrm{R}$ and $\alpha$ were analogous to those of the inner layer $\left(R_{2}\right.$ and $\left.\alpha_{2}\right)$ of the films deposited using $\mathrm{AnSi}(\mathrm{MeOH})$ (Table S3). The variation of $\mathrm{Q}$ with the composition of the treatment solution and with the ex-situ irradiation of the as-deposited hybrid films was less straightforward (Table S3). All Q values were higher than that of the uncoated substrate, but $\mathrm{Q}_{1} \approx \mathrm{Q}_{2}$ and increased similarly with ex-situ photo-oxidation for the case of PySi films, though by a higher amount for $\mathrm{PySi}(\mathrm{MeOH})$. Conversely, $\mathrm{Q}_{2}>\mathrm{Q}_{1}$ and both changed less with ex-situ irradiation for the case of $\mathrm{AnSi}(\mathrm{MeOH})$. The above trends are manifested by the corresponding $\mathrm{C}_{\text {eff, } 1}$ and $\mathrm{C}_{\text {eff,2 }}$ calculated with eq. (4) for the outer and inner layers, respectively (Fig. 11). By comparison with results obtained for FTO substrates (Fig. 9), the $C_{\text {eff }}$ values are much smaller, but vary similarly with ex-situ photo-oxidation, despite of $\mathrm{C}_{\text {eff, } 2}>\mathrm{C}_{\text {eff, }, 1}$ in the case of $\mathrm{AnSi}(\mathrm{MeOH})$. For $\mathrm{AnSi}(\mathrm{MeOAc}$ ) (Fig. 11b), the as-deposited and ex-situ irradiated films

(b)

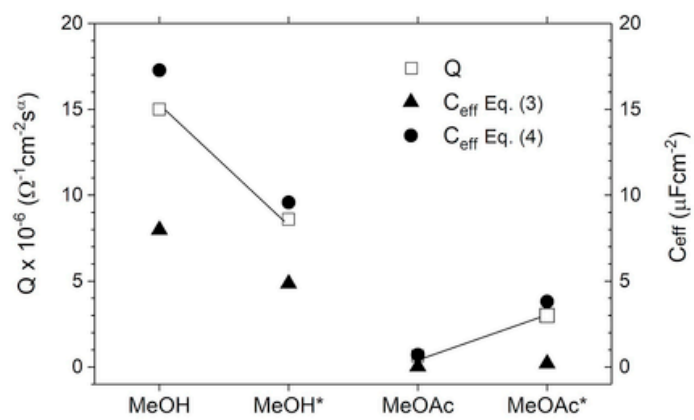

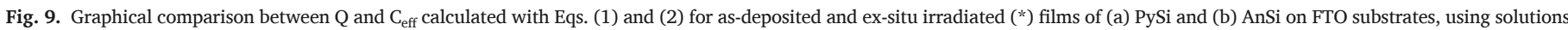
containing either $\mathrm{MeOH}$ or $\mathrm{MeOAc}$ in excess. 
(a)

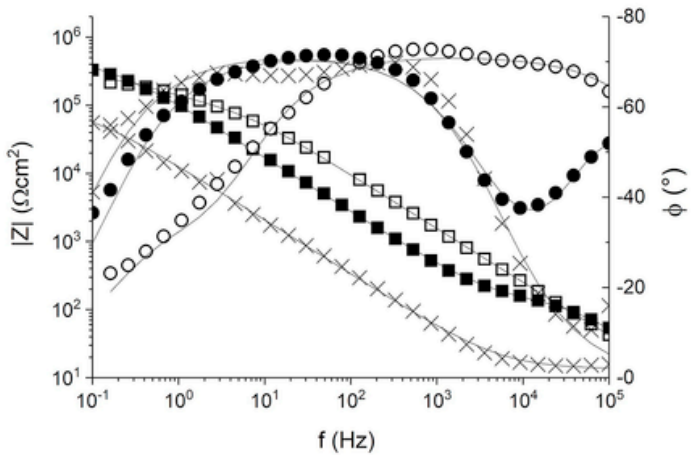

(c)

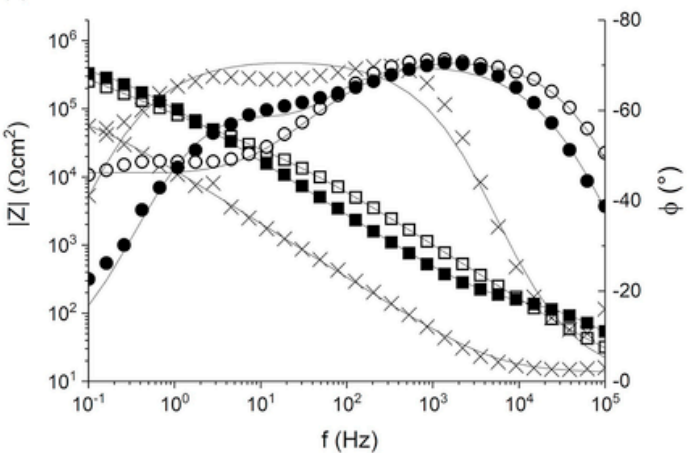

(b)

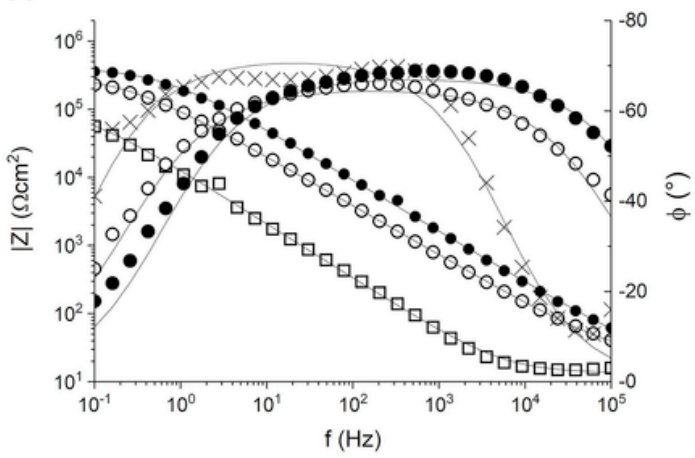

(d)

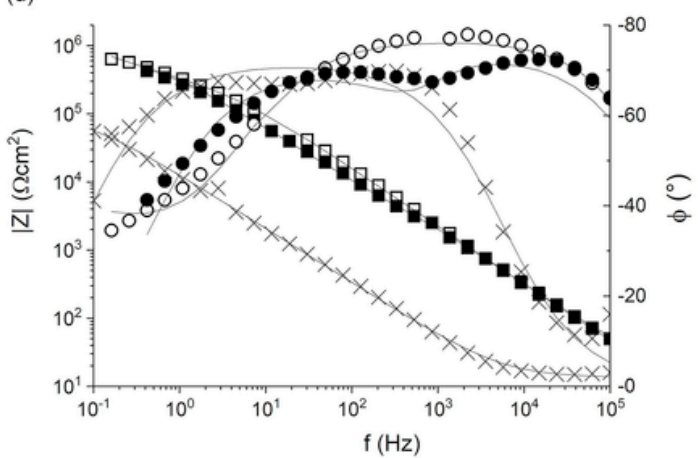

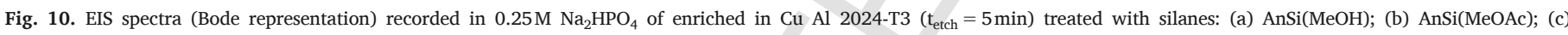

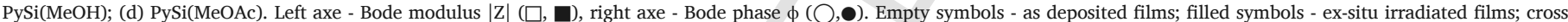
symbols - Bode modulus and phase of the uncoated Al 2024-T3 $\left(\mathrm{t}_{\text {etch }}=5 \mathrm{~min}\right)$.

(a)

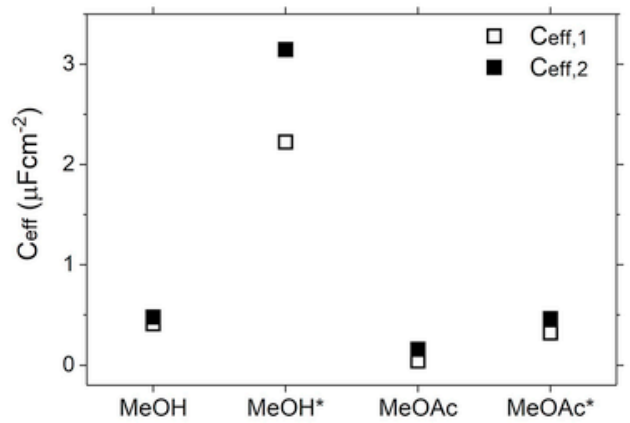

(b)

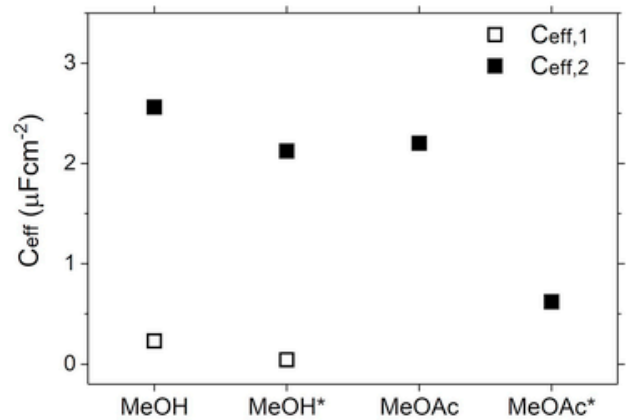

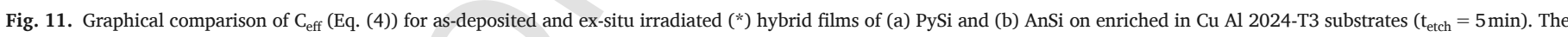
subscripts 1 and 2 indicate the outer and inner stratums, respectively.

present $\mathrm{C}_{\text {eff }}$ values closely equal to $\mathrm{C}_{\text {eff,2 }}$ and $\mathrm{C}_{\text {eff, }, 1}$, respectively, of the parent $\mathrm{AnSi}(\mathrm{MeOH})$ treatment.

Results point out that deposition of hybrid films on enriched in $\mathrm{Cu} \mathrm{Al}$ 2024-T3 leads to a highly resistive and heterogeneous inner layer, being consistent with the formation of heteronuclear oxane bonds (Al-O-Si) at the metal/film interface during the surface treatment step. However, this only does not justify the higher charge storage/exchange capacity for the case of $\mathrm{AnSi}(\mathrm{MeOH})$ (Fig. 11b), unless $\mathrm{Cu}-\pi(\mathrm{N})$ complexation is considered $[4,5,21]$. Copper species acting as redox mediators promote $\mathrm{Cu}^{+}(\pi$-ligand) coordination in the presence of semiquinone moieties and the consequent blocking of active sites. The structural and energetic heterogeneity throughout the film thickness is thus more significant. Release of $\pi$-ligand upon photoexcitation due to weaker $\mathrm{Cu}-\pi(\mathrm{N})$ complexation is suggested for the case of $\mathrm{AnSi}(\mathrm{MeOAc})$ treatments (Fig. 11b). The charge storage/exchange behavior of PySi films is primarily determined by the extent of interpenetration of the $\sigma$ - $\pi$ conjugated hybrid network, corroborating previous findings $[6,9]$, while $\mathrm{Cu}-\pi(\mathrm{N})$ interactions play a less important role.

\subsection{Impedance behavior in aggressive $\mathrm{NaCl}$ solutions}

The Nyquist diagrams collected in $0.6 \mathrm{M} \mathrm{NaCl}$ solutions for the enriched in $\mathrm{Cu} \mathrm{Al} 2024-\mathrm{T} 3$ treated with silanes $\left(\mathrm{E}_{\mathrm{oc}} \approx-0.60 \mathrm{~V}\right)$ were featured by a depressed capacitive semicircle and inductive points in the limit of low frequencies (Fig. 12a and b). Similar results were obtained in more dilute test solutions $\left(0.01 \mathrm{M} \mathrm{NaCl}, \mathrm{E}_{\mathrm{oc}} \approx-0.50 \mathrm{~V}\right)$, as shown in Fig. 12 (insets) for some conditions. The corresponding Bode plots differed from those reported in Fig. 10 by the decrease of $|\mathrm{Z}|$ values at $\mathrm{f}<1 \mathrm{~Hz}$, in addition to the presence of only one peak in the $\phi-\mathrm{f}$ plots and $\phi$ values below $-20^{\circ}$ at $\mathrm{f}<1 \mathrm{~Hz}$. The experimental points fitted best the equivalent circuit in Fig. $6 c$ (Table S4), where circuit elements $\mathrm{CPE}|| \mathrm{R}_{\mathrm{ct}}$ and inductance $\mathrm{L}$ are related to the charge transfer behavior of 
(a)

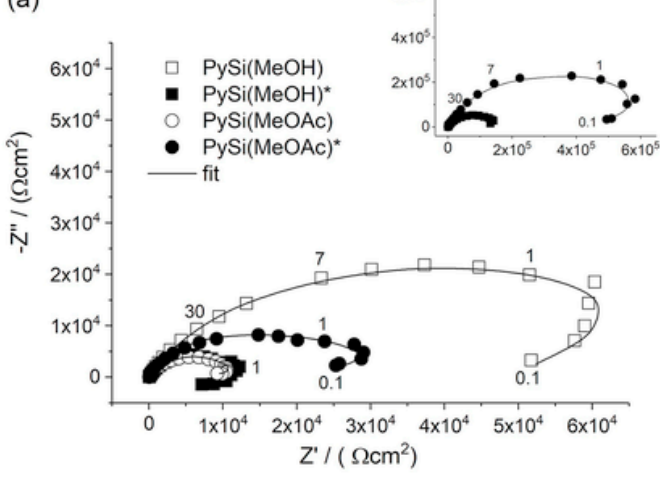

(b)

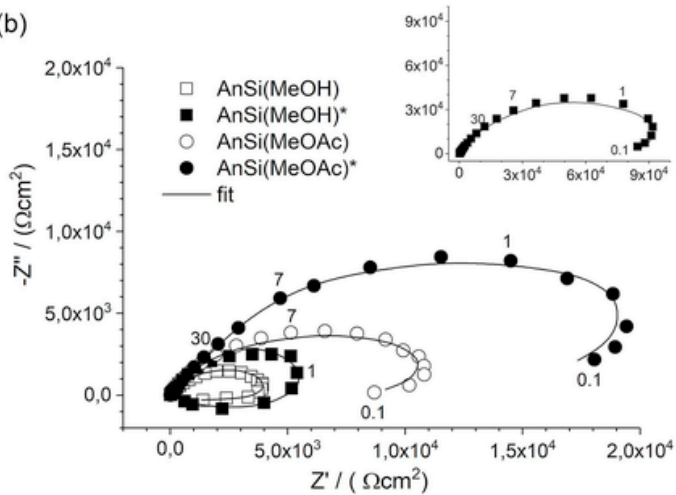

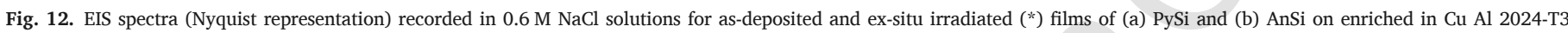
$\left(\mathrm{t}_{\text {etch }}=5 \mathrm{~min}\right)$. Insets: selected spectra recorded in $0.01 \mathrm{M} \mathrm{NaCl}$. Numbers near the traces indicate frequency in $\mathrm{Hz}$

the filmed surface and to localized processes at the buried metal/film interface. No inductive points but a second capacitive loop was obtained in the case of uncoated substrates (Fig. S2, Table S1), being related to diffusion of charged species such as $\mathrm{Al}$ (hydr)oxychlorides and cooper chloride complexes (e.g. $\mathrm{CuCl}_{2}{ }^{-}$) produced as a result of coupled cathodic/anodic reactions at the metal/solution interface [22,23]. It is well known that microgalvanic corrosion driven by ORR dominates at open circuit in chloride solutions. Microgalvanic corrosion is enhanced as local corrosion elements of galvanic type develop with $\mathrm{Cu}$ re-deposition [24-26]., this being promoted with alkaline etching and during corrosion (Fig. S2) [13]. The inductive phase shift in the current with surface modification manifests cooperative electron-transfer steps that block the diffusion of intermediates of corrosion products [27-31]. The displacement of the dissolution path as a result of a kinetically-induced blocking effect is consistent with the mixed barrier/active protection of the hybrid films [1-5]. The higher contribution of the inductive response obtained for the case of AnSi treatments (Fig. 12) correlates with the interconversion between different redox states due to changes in local $\mathrm{pH}$ and to metallo-complexation of the aniline moieties [3-5,10,11], being assisted by the easier penetration of $\mathrm{Cl}^{-}$through the p-type semiconducting film. Inductive loops have been reported for electrochemically deposited polyaniline on $\mathrm{Pt}$ in $1 \mathrm{M} \mathrm{HCl}$ [32] and, more recently, for iron oxide covered with phenyl-capped aniline tetramers in $3.5 \mathrm{wt} \%$ $\mathrm{NaCl}$ [33].

It is to be noticed that the diagrams collected in $0.6 \mathrm{M} \mathrm{NaCl}$ for the case of $\mathrm{AnSi}(\mathrm{MeOH})$ treatments show some symmetry above and below the $\mathrm{Z}^{\prime}$ axe (Fig. 12b), indicating that the concentration impedance of the free sites adds to the faradaic impedance for an electrochemical reaction involving different adsorbates [28]. Since the $\mathrm{Cu}^{+}(\pi$ ligand) promoted during the surface treatment should behave as a Lewis base, displacement reactions due to protonic acid doping and formation of $\mathrm{Al}$ chloride - aniline adducts may account for the significant reorganization of the reacting interface with $\mathrm{Cl}^{-}$attack. The decrease of the inductive points with dilution of the test solution and thus with increasing dissolved oxygen concentration is consistent with disfavored ORR at the buried interface as reduced aniline units are stabilized by complexation.

Displacement reactions justify the structured "extraction" of copper species observed for the as-abraded alloy surface modified with AnSi (MeOH) during exposure in $\mathrm{NaCl}$ (Fig. 13 in Ref. [4]), in support to in-situ $\mathrm{Cu}-\pi(\mathrm{N})$ interactions decreasing the $\mathrm{Al}-\mathrm{Cu}$ microgalvanic coupling $[1,4,5]$. The barrier performance and thus the stability of the metal/film interface are higher for the case of n-type PySi film, as highlighted by the higher and smaller dimensions of the capacitive and inductive loops, respectively, for the case of $\mathrm{PySi}(\mathrm{MeOH})$ (Fig. 12a). The environmentally-friendly MeOAc-based treatment appears ular for AnSi (Fig. 12b). Nonetheless, the conditions used in this work simulate the first stages of localized dissolution processes. The effect of prolonged exposure [1-5] on impedance is still to be studied.

\section{Conclusions}

The semiconducting and electrical properties of PySi and AnSi films on inert FTO and reactive Cu-rich Al 2024-T3 substrates were investigated using different approaches. The hybrid films are photoactive and present semiconducting behavior due to the presence of pyrrole and aniline moieties in the hybrid network. The n-type semiconducting behavior of PySi film corroborates the trend for cooperative non-covalent $\mathrm{OH}-\pi$ interactions and the resulting charge pinning action of $\mathrm{SiOH}$. The more basic aniline derivative favoring the deprotonation of $\mathrm{SiOH}$ leads to p-type semiconducting AnSi films, as typically obtained for polyaniline and derivatives. $\mathrm{Cu}-\pi(\mathrm{N})$ interactions play a minor role in the photo-doping processes.

The electrical properties of the hybrid films depend on the extent of formation of $\mathrm{OH}-\pi$ and $\mathrm{N}-\mathrm{H} \cdot \cdots \mathrm{N}$ donor-acceptor complexes with hydrolysis in the treatment solution. More resistive films for the treatment solutions containing polar but aprotic $\mathrm{MeOAc}$ in excess correlates with the smaller contribution to the hybrid film network of charge transfer complexes. Specific interactions at the metal/solution interface during the surface modification are of importance also. Differently from FTO, a two-layer film structure is formed on enriched in $\mathrm{Cu} \mathrm{Al} \mathrm{2024-T3.} \mathrm{The}$ highly resistive and heterogeneous inner layer is consistent with the formation of heteronuclear oxane bonds (Al-O-Si) at the metal/film interface during surface treatment step. The related charge storage/exchange capacity depends on the propensity towards $\mathrm{Cu}-\pi(\mathrm{N})$ specific interactions, the AnSi derivative being more prone to $\mathrm{Cu}^{+}(\pi$-ligand) coordination. The consequent blocking of the active sites makes the interface more resistive but in non-aggressive to $\mathrm{Al}$ passivity $\mathrm{Na}_{2} \mathrm{HPO}_{4}$. In aggressive chloride solutions, the interface reactivity increases markedly due to the easier penetration of these species through the p-type semiconducting film, contrariwise to the n-type semiconducting PySi film. Nevertheless, cooperative redox transfer reactions hinder the diffusion of corrosion products. The kinetically-induced blocking effect is attributed to displacement reactions due to protonic acid doping and formation of $\mathrm{Al}$ chloride - aniline adducts as the $\pi$-ligand is released.

\section{Acknowledgments}

The authors wish to thank F. Difranco, M. Santamaria, and F. Diquarto (University of Palermo, Italy) for facilities in performing photocurrent spectroscopy experiments and for helpful discussions. The experimental work done by the past student I. Bertoli is gratefully acknowledged. 


\section{Appendix A. Supplementary data}

Supplementary data related to this article can be found at https:// doi.org/10.1016/j.matchemphys.2018.06.042.

\section{References}

[1] (a) M. Trueba, S.P. Trasatti, Pyrrole-based silane primer for corrosion protection of commercial Al alloys. Part I: synthesis and spectroscopic characterization, Prog. Org. Coating 66 (2009) 254-264;

(b) M. Trueba, S.P. Trasatti, Part II. Corrosion Performance in Neutral NaCl Solution, 2009265-275.

[2] M. Trueba, S.P. Trasatti, D. Flamini, Hybrid coatings based on conducting polymers and polysiloxane chains for corrosion protection of $\mathrm{Al}$ alloys, Adv. Mater. Res. 138 (2010) 63-78.

[3] D.O. Flamini, M. Trueba, S.P. Trasatti, Aniline-based silane as a primer for corrosion inhibition of aluminium, Prog. Org. Coating 74 (2012) 302-310.

[4] M. Trueba, S.P. Trasatti, D.O. Flamini, The effect of aluminium alloy secondary phases on aniline-based silane protection capacity, Corrosion Sci. 63 (2012) 59-70

[5] S. Bianchi, M. Trueba, S.P. Trasatti, E. Madaschi, M.C. Sala, An in-depth comprehension of the protection mechanism of $\mathrm{Al}$ alloys by aniline-based silane, Prog. Org. Coating 77 (2014) 2054-2065.

[6] S. González-Santana, C. Morera-Boado, L.A. Montero-Cabrera, M. Trueba, S.P. Trasatti, Pyrrolyl-silicon compounds as precursors for donor-acceptor systems stabilized by noncovalent interactions, J. Phys. Chem. 119 (2015) 7038-7051.

[7] E. Volpi, L. Falciola, M. Trueba, S.P. Trasatti, M.C. Sala, E. Pini, A. Contini, Pyrrolyl-silicon compounds with different alkyl spacer lengths: synthesis, electrochemical behavior and binding properties, Synth. Met. 231 (2017) 127-136.

[8] C. Santi, G. Conchetto, M. Trueba, S.P. Trasatti, Electrochemical characterization of organo-functionalized silanes as precursors for surface treatments, Metall. Ital. 109 (2017) 19-22.

[9] G. Conchetto, C. Santi, M. Trueba, S.P. Trasatti, Macromolecular aggregation and electrochemical behavior of pyrrolyl-, anilynyl- and thiophenyl-silicon compounds as precursors for thin hybrid films, Prog. Org. Coating 2018 (https;//doi.org/ 10.1016/j.porgcoat.2018.05.010)()

[10] A.J. Heeger, Semiconducting and metallic polymers: the fourth generation of polymeric materials, J. Phys. Chem. B 105 (2001) 8475-8491.

[11] J. Heinze, B.A. Frontana-Uribe, S. Ludwigs, Electrochemistry of conducting polymers - persistent models and new concepts, Chem. Rev. 110 (2010) 4724-4771.

[12] C. Ruan, Z. Yang, M.T. Rodgers, Influence of the d orbital occupation on the nature and strength of copper cation- $\pi$ interactions: threshold collision-induced dissociation and theoretical studies, Phys. Chem. Chem. Phys. 9 (2007) 5902-5918.

[13] M.A. Jakab, D.A. Little, J.R. Scully, Experimental and modeling studies of the oxygen reduction reaction on AA2024-T3, J. Electrochem. Soc. 152 (2005) B311-B320.

[14] Y. Wang, L. Yin, Y. Jin, J. Pan, C. Leygraf, Numerical simulation of micro-galvanic corrosion in $\mathrm{Al}$ alloys: steric hindrance effect of corrosion product, J. Electrochem. Soc. 164 (2017) C1035-C1043.

[15] F. La Mantia, M. Santamaria, F. Di Quarto, H. Habazaki, Physicochemical characterization of thermally aged anodic films on magnetron sputtered niobium, J. Electrochem. Soc. 157 (2010) C258-C267.
[16] M. Santamaria, F. Di Quarto, H. Habazaki, Influences of structure and composition on the photoelectrochemical behaviour of anodic films on $\mathrm{Zr}$ and $\mathrm{Zr}-20$ at.\%Ti, Electrochim. Acta 53 (2008) 2272-2280.

[17] F. Di Quarto, F. La Mantia, M. Santamaria, Physicochemical characterization of passive Films and corrosion layers by differential admittance and photocurrent spectroscopy, Ch. 4, in: S.I. Pyun, J.W. Lee (Eds.), Modern Aspects of Electrochemistry N. 46: Progress in Corrosion Science and Engineering, () Springer Science + Business Media, LLC, 2009, pp. 231-316, (ISBN 978-0-387-92262-1).

[18] F. Di Quarto, M. Santamaria, P. Skeldon, G.E. Thompson, Photocurrent spec troscopy study of passive films on hafnium and hafnium-tungsten sputtered alloys, Electrochim. Acta 48 (2003) 1143-1156.

[19] V.V. Afanas'ev, Internal Photoemission Spectroscopy, Fundamentals and Recent Advances, Elsevier, 2014, (ISBN: 9780080999296).

[20] B. Hirschorn, M.E. Orazem, B. Tribollet, V. Vivier, I. Frateur, M. Musiani, Determination of effective capacitance and film thickness from constant-phase-element parameters, Electrochim. Acta 55 (2010) 6218-6227.

[21] T. Hirao, Conjugated systems composed of transition metals and redox-active $\pi$-conjugated ligands, Coord. Chem. Rev. 226 (2002) 81-91.

[22] D. Batocchi, A.M. Simoes, D.E. Tallman, G.P. Bierwagen, Comparison of testing solutions on the protection of $\mathrm{Al}$-alloys using a Mg-rich primer, Corrosion Sci. 48 (2006) 2226-2240.

[23] K.F. Khaled, Studies of the corrosion inhibition of copper in sodium chloride solutions using chemical and electrochemical measurements, Mater. Chem. Phys. 125 (2011) 427-433.

[24] H.M. Obispo, L.E. Murr, R.M. Arrowood, E.A. Trillo, Copper deposition during the corrosion of aluminum alloy 2024 in sodium chloride solutions, J. Mater. Sci. 35 (2000) 3479-3495.

[25] T.J.R. Leclère, R.C. Newman, Self-regulation of the cathodic reaction kinetics during corrosion of AlCu alloys, J. Electrochem. Soc. 149 (2002) B52-B56.

[26] A.E. Hughes, R. Parvizi, M. Forsyth, Microstructure and corrosion of AA2024, Corrosion Rev. 33 (2015) 1-30.

[27] C. Cao, On the impedance plane displays for irreversible electrode reactions based on the stability conditions of the steady-state-II. Two state variables besides electrode potential, Electrochim. Acta 35 (1990) 837-844.

[28] J.P. Diard, B. LeGorrec, C. Montella, C. Montero-Ocampo, Calculation, simulation and interpretation of electrochemical impedance diagrams: Part IV. Second-order electrochemical impedances, J. Electroanal. Chem. 352 (1993) 1-15.

[29] P. Cordoba -Torres, M. Keddam, R.P. Nogueira, On the intrinsic electrochemical nature of the inductance in EIS - a Monte Carlo simulation of the two-consecutive steps mechanism: the rough 3D case and the surface relaxation effect, Electrochim. Acta 54 (2009) 6779-6787.

[30] P. Cordoba -Torres, R.P. Nogueira, Kinetic macroscopic description of the microscopic structure of dissolving interfaces: influence of the electrochemical kinetics, Electrochim. Acta 53 (2008) 4805-4817.

[31] X. Li, S. Deng, X. Xie, Experimental and theoretical study on corrosion inhibition of o-phenanthroline for aluminum in $\mathrm{HCl}$ solution, J. Taiwan Inst. Chem. Eng. 45 (2014) 1865-1875.

[32] W.-C. Chen, T.-C. Wen, A. Gopalan, Negative capacitance for polyaniline: an analysis via electrochemical impedance spectroscopy, Synth. Met. 128 (2002) 179-189.

[33] T. Chowdhury, A. Mohtasebi, S. Kostina, X. Zhang, J.R. Kish, P. Kruse, Interactions of different redox states of phenyl-capped aniline tetramers with iron oxide surfaces and consequences for corrosion inhibition, J. Electrochem. Soc. 164 (2017) C1013-C1026. 